\title{
AJUSTE A LA CALIFICACIÓN DEL RIESGO DE MERCADO DE LAS ACCIONES MÁS VOLÁTILES QUE CONFORMAN EL ÍNDICE DE PRECIOS Y COTIZACIONES DE LA BOLSA MEXICANA DE VALORES, CON LA IMPLEMENTACIÓN DE UNA RED NEURONAL ARTIFICIAL CLASIFICADORA
}

\section{Esther Guadalupe Carmona Vega*}

Universidad Autónoma de Ciudad Juárez, Departamento de Ciencias Administrativas Segundo Lugar en el Premio Nacional Bolsa Mexicana de Valores 2011

(Recibido 22 de julio 2012, aceptado 28 de noviembre 2012)

\begin{abstract}
Resumen
En México, la aplicación de Redes Neuronales Artificiales en finanzas se ha enfocado en el estudio del análisis del riesgo de crédito; empleándolas para ajustar los resultados de indicadores bursátiles. Sin embargo, esta investigación en particular, las utiliza para establecer un ajuste a la medición y clasificación del riesgo de mercado; mostrando los resultados obtenidos en la fase experimental de los procesos de entrenamiento y prueba en la segunda etapa de simulación de la red; los cuales han alcanzado un nivel de categorización arriba del $70 \%$, mostrando las variables que contribuyen significativamente a la medición y clasificación del riesgo sistémico.
\end{abstract}

\begin{abstract}
In Mexico, the Artificial Neuronal Network applicated to the finances has focused in the study of the analysis of the credit risk; and to fit the results of stock-exchange indicators that offer useful information to the financial investors. Nevertheless, in this case in particular, this tool it is used to measure and classified the Mexican market risk; showing the results obtained in the experimental phase of the training and test in the second simulation stage of the network; reaching a classification rate of over $70 \%$, presenting the variables that significantly contribute to the measurement and classification of the systematic risk.
\end{abstract}

Clasificación JEL: F17, GI, G12 E58

Palabras clave:Redes Neuronales Artificiales, Riesgo de Mercado, Modelo de Valuación de Activos de Capital (MVAC), Entidades Calificadoras de Riesgo.

\footnotetext{
* Calle de las Rosas No 1280, Colonia Tercera Burócrata, Ciudad Juárez Chihuahua; C.P. 32360. Tel. (01 656) 61121 27. Correo electrónico:esther.carmona@uacj.mx
} 


\section{Introducción}

En todo proceso inherente a los mercados financieros, el objetivo de los oferentes y compradores es garantizar un máximo rendimiento con un mínimo de riesgo, originando que la variabilidad en las transacciones financieras cada vez genere menores condiciones de incertidumbre, particularmente en las operaciones más predominantes de los mercados bursátiles, como lo son la compra y venta de acciones que crean fuertes movimientos en las economías, particularmente por el efecto que tienen los mercados en factores económicos tales como la inflación, el tipo de cambio, las tasas de interés, la liquidez y el apalancamiento financiero de las empresas, los cuales afectan directamente la maximización de la rentabilidad del mercado, equilibrando objetivamente el riesgo en las operaciones de inversión de los grandes capitales.

Sin embargo, para compensar el incremento de los niveles del riesgo de mercado, una inversión debe ofrecer la posibilidad de lograr mayores ganancias. Por lo tanto, si el inversionista se informa y decide asumir cierto riesgo, tiene la probabilidad de obtener un rendimiento mayor. Éste es un principio fundamental en finanzas y se denomina relación riesgo/rendimiento. Esta relación refleja la predisposición a aceptar ganancias y pérdidas (cambios, inseguridad, volatilidad) en el corto plazo, teniendo en mente una perspectiva de ganancia neta en el largo plazo, que será superior a las utilidades que se asocian con las inversiones estables (aquellas que no conllevan riesgos de pérdida). La estabilidad en sí misma está también sujeta a su propia forma de incertidumbre, un hecho muy a menudo no tomado en cuenta por los inversionistas que buscan la seguridad.

La volatilidad es una característica fundamental de las operaciones bursátiles modernas, cuyo cálculo y previsión es de vital importancia para los que en ellas operan. Ésta, es una medida de la velocidad de las mismas, que marca qué tan rápido se ajustan los precios de los activos financieros ante determinados hechos. Los mercados se mueven despacio o deprisa, considerándose como de baja ó alta variabilidad.

\subsection{Definición del problema}

Considerando que el riesgo de mercado, es uno de los fenómenos más recurrentes en las finanzas, debido particularmente a la alta volatilidad que actualmente afecta a los mercados internacionales, es un tema valioso para ser investigado en las unidades económicas en el mundo; por lo que México no debe ser la excepción y se le debe dar la importancia que implica, en una economía en constante movimiento, particularmente por las características de su entorno, que afecta fuertemente las operaciones financieras en los mercados bursátiles al tener movimientos fuertes en los precios de las acciones que constituyen sus capitales.

En los últimos años, los movimientos a la alza y a la baja en el tipo de cambio, y la variación en las tasas de interés, son algunos factores que elevan la crisis financiera que actualmente sigue afectando a las finanzas públicas y privadas; esta situación se ha venido extendiendo fuertemente desde el año 2008 con los problemas del crédito hipotecario mundialmente conocido como un efecto de la economía estadounidense, que repercutió como onda de contagio principalmente en la economía local, provocando movimientos bruscos en los 
mercados de capitales, como la Bolsa Mexicana de Valores (BMV) con fuertes implicaciones en el mercado internacional, donde la mayoría de los accionistas e inversionistas nacionales, paralelamente han tenido que enfrentar situaciones más riesgosas, como los movimientos bursátiles de la Bolsa de New York y el mercado asiático, por mencionar algunos; afectando directamente la estructura económica y financiera no solamente de los mercados sino de las economías a nivel mundial.

Este panorama de recurrentes crisis, ha originado que dentro de los estudios financieros y económicos, surjan nuevas propuestas de modelos de predicción que ajusten y reduzcan estas condiciones peculiares de volatilidad, y que contribuyan a resolver de manera objetiva los diferentes factores de riesgo de inversión de los grandes capitales que se mueven en las actividades de compra y venta de activos bursátiles. Con el transcurso del tiempo, se ha podido obtener más información y nuevas metodologías que ayudan a una tener una mejor percepción de la variabilidad en el mercado; esto ha permitido contar con mayores elementos científicos para comprender la aparición de este fenómeno, y minimizar sus efectos sobre los diversos entes económicos (Oddone, 2004).

De manera que, en este estudio se aborda la medición y clasificación del riesgo de mercado bursátil mexicano, donde como en cualquier actividad de comercialización de instrumentos de inversión o financiamiento, la variación en el precio y el volumen de las transacciones es un movimiento que constantemente afecta las operaciones de la Bolsa Mexicana de Valores. Por lo anterior, es trascendental beneficiar a todos los que intervienen en el mercado con información oportuna y adecuada, sobre cómo esa multiplicidad de factores económicos, afecta directa o indirectamente el cálculo objetivo del riesgo sistémico en la compra y venta de los instrumentos, y cuántos de ellos presentan mayor incertidumbre a través de los movimientos históricos, acelerando la movilidad de los capitales de los diferentes grupos nacionales e internacionales que continuamente hacen parte del mercado accionario mexicano.

\subsection{Objetivos de la investigación}

1. Establecer si la medición de la calificación del riesgo de mercado de las empresas más activas que cotizan en la Bolsa Mexicana de Valores, medido por la beta, puede clasificarse adecuadamente al aplicar un modelo de Red Neuronal Artificial (RNA) Clasificadora.

2. Estudiar, definir y calificar el riesgo de mercado mexicano aplicando un modelo de Red Neuronal Artificial Clasificadora, para clasificarlo en varios niveles, y posteriormente comparar los resultados obtenidos con las escalas que utilizan las principales Entidades Calificadoras de Riesgo (ECR) en México, las cuales constituyen la base para que los agentes económicos tengan un indicador objetivo en las decisiones de inversión y financiamiento de las operaciones bursátiles.

\subsection{Hipótesis de la investigación}

Hipótesis $H_{0}$ : El uso del modelo de Redes Neuronales Artificiales en la medición del riesgo de mercado, agregando las variables: tipo de cambio (peso mexicano vs. dólar americano), tasa de interés interbancaria de equilibrio (TIIE) y los rendimientos accionarios (precio final de la acción), reflejan de 
manera adecuada la clasificación y calificación de las emisoras seleccionadas, al ser comparado con la medición de las Entidades Calificadoras de Riesgo (ECR) nacionales.

Hipótesis $H_{1}$ : El uso del modelo de Redes Neuronales Artificiales en la medición del riesgo de mercado, agregando las variables: tasa libre de riesgo (Cetes a 91 días), el rendimiento del mercado (RA) y la tasa de rendimiento requerida $(\mathrm{Kj})$, reflejan de manera adecuada la clasificación y calificación de las emisoras seleccionadas, al ser comparado con la medición de las Entidades Calificadoras de Riesgo (ECR) nacionales.

\subsection{Determinación de las variables seleccionadas en las fases de simulación}

Se tomó la inflación porque como variable económica, es un factor que incrementa la incertidumbre en los mercados financieros y constituye la base fundamental de la administración de la política monetaria mexicana, por lo tanto, ésta influye en las decisiones sobre el manejo de capitales por parte de las empresas que cotizan o no en la bolsa. Por tal motivo, es importante protegerlos, porque como bien se sabe, con los pesos de ahora dentro de seis meses no se tendrá el mismo poder adquisitivo que con los de hoy, de ahí que, los precios de las acciones involucran intrínsecamente los efectos de la inflación.

En cuanto a la variable tasa de interés, representada por la TIIE si se consideran inversiones de capital, estas operaciones no están libres de riesgo, ya que, en cualquier economía desarrollada o en vías de desarrollo, todos los inversionistas pueden prestar o pedir prestado sus capitales, consecuentemente, en la mayoría de las decisiones de financiamiento a través del mercado bursátil, se debe considerar la utilización de una tasa libre de riesgo, para que las operaciones se mantengan en equilibrio.

No se puede hablar de cualquier tipo de riesgo, sino se menciona que las tasas de interés involucran movimientos en el mercado crediticio, como es el caso de invertir en bonos (deuda) que denota cierto porcentaje de pago o beneficio que obtiene el inversionista por tomar esta opción, que implica un riesgo menor, ya que es una renta fija. Sin embargo, hay factores de riesgo inherentes a la transacción, que en el caso de la emisión de deuda, estaría representado por el costo de financiamiento que adquiere la empresa en el momento de poner en el mercado estos instrumentos.

En el mercado de valores, la emisión de acciones afecta la variabilidad de las tasas de interés, ocasionando una mayor volatilidad en el mercado (títulos de deuda pública), que se verá reflejada directamente en el precio de todos los valores que ofertan y demandan las entidades que cotizan en la bolsa, generando una disminución o incremento del riesgo sistémico.

En este contexto, entonces tanto los inversores nacionales como extranjeros, deben tomar decisiones de inversión y financiamiento, tales como la compra y venta de activos financieros (acciones). Por tanto, es de suma importancia que antes de efectuar la operación, el inversor estudie y verifique la situación del tipo de cambio del país, para conocer hasta qué punto la política monetaria lo tiene controlado o no.

Además, es importante saber si se cuenta con un libre mercado de divisas, el cual influye en los flujos de efectivo y de capitales, además de estar al tanto 
del grado de volatilidad del mercado, y el riesgo al que están sometidas las inversiones; todo ello para conocer qué tan dispuestos están los inversionistas para asumir situaciones de incertidumbre y medir el efecto que tendría en la rentabilidad esperada.

De manera que, una política económica y monetaria sana, consiste en el proceso de manipular eficientemente las variables económicas para generar estrategias de crecimiento sostenible en los diferentes sectores financieros de un país. Por tal motivo, esta investigación propone un estudio sobre el ajuste a la medición del riesgo de mercado mexicano donde se muestre, además de los factores económicos más representativos de la economía que han ocasionado la aparición de crisis financieras en el periodo de 2004 a 2009, tales como el precio de las acciones, la cantidad negociada (volumen) y las ganancias de capital ó rendimientos accionarios, otros factores no tan intrínsecos al mercado, como lo son: el tipo de cambio (peso mexicano vs. dólar americano), el nivel de inflación y las tasas de interés (representada por la TIIE a 28 días).

El rendimiento accionario, es medido en términos de la diferencia resultante de los logaritmos naturales (ln) de los precios históricos finales o de cierre de las 18 acciones con mayor bursatilidad, que cotizan en la Bolsa Mexicana de Valores, expresado como: $\left(\ln P_{T+1}-\ln P_{T}\right)$; siendo $\ln P_{T+1}$, el logaritmo natural del precio final y $\ln P_{T}$, el logaritmo natural del precio inicial.

En la primera parte de este estudio, para la hipótesis nula se definió como variable dependiente el riesgo sistemático, y las independientes son la tasa de interés interbancaria de equilibrio (TIIE a 28 días), el tipo de cambio (Peso mexicano vs. Dólar americano) y el rendimiento accionario (Diferencial en los precios).

En la segunda parte, para la hipótesis alternativa o de trabajo, se estudia y analiza la variable dependiente que es el riesgo de mercado, y las independientes ahora son la tasa libre de riesgo (Cetes a 91 días), el rendimiento del mercado (RA) y la tasa de rendimiento requerida $\left(K_{j}\right)$, que son las variables representativas que se usan en el modelo de fijación de precios de activos de capital (CAPM), frecuentemente utilizado en la economía financiera (Johnson, et al., 2005).

\section{Metodología empleada}

Esta investigación propone el modelo de redes neuronales artificiales clasificadoras, como una herramienta innovadora de medición para clasificar y calificar de manera diferente el riesgo sistémico o de mercado, entendido como la pérdida que puede presentar un portafolio, un activo o un título en particular, originada por cambios y/o movimientos adversos en los factores de riesgo (entorno económico) que afectan su precio o valor final; lo cual significa una disminución del patrimonio que puede afectar la viabilidad financiera de la entidad y la percepción que tiene el mercado sobre su estabilidad.

La exploración es cuasi experimental, por lo que fue necesario ampliar la expectativa de estudio para demostrar que el riesgo de mercado no solamente contempla en su medición el precio de las acciones, el volumen de cotización y la tasa libre de riesgo, sino que también hay características económico-financieras que un inversionista está dispuesto a considerar cuando decide entrar al mercado, ya sea como oferente o demandante, tomando como premisa principal 
la rentabilidad esperada que le puede generar la tenencia de los títulos valor (acciones) que desee negociar; de manera que, otro factor inherente en el proceso de negociación es el estudio de la beta, la cual mide la sensibilidad del movimiento del precio de una acción frente a variaciones en el mercado.

Por ende, se sabe que la medición del riesgo sistémico en México, se puede conocer a través de la beta del Índice de Precios y Cotizaciones, que muestra la evolución diaria del nivel general de precios de las acciones operadas en bolsa. La muestra del Índice está integrada por las 35 emisoras más representativas del sector accionario, mismas que se seleccionan bimestralmente de acuerdo al nivel de bursatilidad de los títulos operados, el cual toma en cuenta variables como: número de operaciones, importe negociado, días operados y razón entre el monto operado y el monto suscrito.

Luego entonces, el motivo por el cual se utilizarán redes neurales, es porque hasta ahora en el país la mayoría de los trabajos que existen sobre la medición del riesgo sistémico utilizan diseños convencionales que clasifican el riesgo de mercado tomando en cuenta la beta, como el indicador más importante de la sensibilidad del mercado, representado por el Índice de Precios y Cotizaciones (IPyC), y como referencia para llevar a cabo la calificación del mismo, incluyen las variables correlacionadas: volumen de cotización y precios accionarios.

Para clasificar datos con atributos que están altamente correlacionados, las Redes Neuronales Artificiales han mostrado mejores habilidades de predicción en la valoración de los activos financieros, así como todo tipo de decisiones sobre categorización de los riesgos basados en datos históricos. Este tipo de modelo clasificador, se desempeña mucho mejor que los estructurales tradicionales, como los mínimos cuadrados y los de volatilidad lineal tipo GARCH-Ms (Johnson et al., 2005).

Además de los modelos mencionados anteriormente, existen otros no lineales que sirven para medirlo, como herramientas de proyecciones futuras que han recogido numerosos avances registrados en otras disciplinas; así en el panorama de la predicción financiera actual, en el estudio del riesgo de mercado se ha ido incorporando el desarrollo asociado a las nuevas tecnologías de información, la comunicación (TICs), y el uso de métodos de pronóstico sofisticados, tales como:

- La implementación de sistemas inteligentes, capaces de autoajustar determinados parámetros cruciales en los diseños estadísticos, es lo que se conoce como data mining o minería de datos.

- El uso de herramientas de proyección, que han sido tomadas de la Inteligencia Artificial (IA), de los sistemas inteligentes de optimización y el empleo de técnicas predictivas basadas en desarrollos recientes de la regresión no paramétrica, de la que forman parte los modelos de Redes Neuronales Artificiales (RNA).

La regresión no paramétrica, es una herramienta de modelización que forma parte de la familia de los métodos de ajuste. El objetivo es modelar una variable dependiente "Y" en función de una o varias variables explicativas con el fin de poder prever sus valores, conociendo el peso de las variables explicativas, y los datos observados en el pasado (Cleveland, 1979). 
A partir de los años noventa, tanto el análisis fundamental como el técnico han ido cediendo terreno a los métodos y técnicas de predicción señalados anteriormente. En este contexto, existe evidencia empírica sobre la eficacia para predecir la evolución de los precios de acciones, índices bursátiles, tipos de cambio, tipos de interés, entre otros. Hoy en día, se aplican en las actividades financieras, algunas herramientas matemáticas y estadísticas como: Algoritmos Genéticos, Redes Neuronales Artificiales, Modelos Multivariables, Lógica Difusa, Teoría de Caos y Electromagnetismo (Espinosa, 2005).

La aplicación de las Redes Neuronales Artificiales a las actividades como la gestión de créditos y solvencia en general, se encuentra aún en un estado de desarrollo relativamente temprano, de modo que, muchos de los trabajos que se efectúan actualmente se encuentran aún en fase de exploración; por lo que, al utilizar esta herramienta se pretende continuar con esta línea de investigación en México, implementándola en el campo de las finanzas para la clasificación y calificación del riesgo de mercado.

Por lo anterior, es importante definir que: "Una red neuronal es un modelo matemático simplificado del sistema de procesamiento de información de un ser vivo, que está formada por un conjunto de unidades de procesamiento llamadas neuronas" (Haykin, 1999). La red utilizada es una red clasificadora, la cual ante un conjunto de patrones de entrada, responde con una clasificación de las variables dadas o la información que presenten éstos, con arreglo a un conjunto finito de categorías (Hornik et al., 1989).

\subsection{Estado del arte de las redes neuronales artificiales}

Las redes neurales tras un entrenamiento adecuado, han sido empleadas en el campo de las finanzas, para la toma de decisiones en los siguientes aspectos:

-Investigaciones para la automatización en la concesión de créditos.

-Valoración de riesgo de hipotecas.

-Gestión de proyectos y licitación de estrategias.

-Predicciones económicas.

-Detección de irregularidades en los movimientos de los precios de las acciones.

-Identificación de factores económicos explicativos (Deboeck, 1994).

- Asimismo, han sido sugeridas como herramientas valiosas para realizar predicciones sobre los rendimientos o la volatilidad de los mercados financieros, así como a la hora diseñar estrategias técnicas de contratación (Fernández, et al., 2001).

La posibilidad de diseñar cierto tipo de redes neuronales para el reconocimiento de irregularidades en series temporales de naturaleza altamente no lineal, posibilitan otro tipo de aplicaciones a las finanzas, todavía prácticamente casi inéditas en las bolsas de valores, empleando las redes para el diseño de reglas técnicas de medición. En este sentido, las redes presentan diversas limitaciones o desventajas:

1.En general, una red no debe ser usada para modelar relaciones lineales inherentes (Cruz, 2007). 
2. No pueden proporcionar respuestas precisas y sólo indicaran ciertos rangos, por ejemplo, las redes clasificadoras no tienen la facilidad de explicar cómo se llega a determinada conclusión.

3. No pueden justificar sus respuestas y no tienen la facilidad para igualar el cómo y el porqué de los sistemas expertos programables, por lo que, las redes pueden considerarse como cajas negras.

4. Son muy sensibles a los datos con los que se les ha entrenado (Van Eyden, 1996).

Pese a ello, las Redes Neuronales Artificiales han demostrado tener las siguientes ventajas en el ámbito financiero:

1. Las redes aplicadas como modelos no paramétricos pueden incorporar fácilmente múltiples fuentes sin simplificar consideraciones relativas a la forma funcional de la relación entre las variables de salida y las predictivas. Se les considera como métodos estadísticos no lineales, que ofrecen ciertas ventajas sobre sus contrapartes paramétricas (Cruz, 2007).

2. Gran poder y flexibilidad para detectar relaciones no lineales complejas. Es decir, las RNA deben ser aplicadas cuando exista alguna evidencia de no linealidad en las relaciones entre las variables dependientes y explicativas.

3. Su empleo en las finanzas es cada día más frecuente, llegando a incidir en temas trascendentales como pueden ser los productos derivados, cuyas fórmulas de valoración son altamente no lineales incluso cuando están disponibles en expresión analítica.

4. Permiten abordar el complejo problema del desarrollo de estrategias dinámicas de cobertura (Hutchinson et al., 1994).

Desde el año 2000 en adelante, otros investigadores las utilizan en la obtención de pronósticos, como es el caso de Chile, representado por Parisi, et al. $(2002,2003)$ quienes estudiaron la capacidad de predicción en el signo de las variaciones semanales de los índices bursátiles CAC40, Hang Seng, KLSE, MMX, STI, Dow Jones Industry, S\&P500, GDAX, Bovespa, Nikkei225 y FTSE100, obteniendo un nivel de predicción del 50\%; independientemente de la significancia estadística de la capacidad predictiva, las redes usadas elevaron la rentabilidad o redujeron las pérdidas. A partir de esa fecha, autores tales como Shah y Murtaza (2000) y Atiya (2001), las aplicaron para analizar las quiebras corporativas; también las RNA han sido eficaces en el análisis de los precios de activos. A su vez, Sánchez (2003), trabajó sobre la situación financiera de las instituciones bancarias españolas de 1990 al 2001, demostrando los beneficios obtenidos en la aplicación de las redes, para estimar las quiebras y predecir los rendimientos de las carteras de valores.

En España, Corredor y Santamaría (2004), realizan comparaciones diversas en la predicción de las opciones sobre el índice IBEX 35, validando la eficiencia del mercado de opciones español por medio de un test con respecto a la predicción de volatilidad. En todos estos modelos predicitivos, hay que destacar el trabajo de los Doctores Zhang, Jiang y Li (2004), quienes en sus investigaciones diseñaron un modelo de RNA multicapa de propagación hacia atrás, proyectando las futuras tendencias en las actividades de compra y venta de valores para una adecuada toma de decisiones. Asimismo, Lamothe y García (2004), trabajaron sobre un algorítmico matemático que explicó la 
volatilidad inherente de las opciones sobre el índice bursátil IBEX35, concluyendo al igual que Qi (1999), que el modelo de Black Scholes no es eficiente totalmente y que las RNA crean algoritmos que permiten mejores pronósticos; también Hamid y Habib (2005), aplican esta herramienta en la valoración de opciones, concluyendo que este modelo es mucho mejor para predecir el precio de la opción así como su variabilidad.

En México, Gómez y Mendoza (2009), realizaron un trabajo de exploración sobre las "Herramientas para el Pronóstico de la Calificación Crediticia de las Finanzas Públicas Estatales en México: Redes Neuronales Artificiales, Modelo PROBIT Ordenado y Análisis Discriminante", obteniendo el segundo lugar en la categoría de Investigación del Premio Nacional de Mercados Financieros, organizado por la BMV.

Como se puede observar, la mayoría de los estudios de Redes Neuronales Artificiales en las finanzas, han aplicado redes optimizadoras de aprendizaje, pero pocos usan las redes clasificadoras de reconocimiento de patrones que también aprenden.

Dado que, en los mercados la variabilidad en los precios de los instrumentos bursátiles genera el denominado riesgo sistémico, para aminorarlo se utiliza la diversificación de las inversiones con el uso de portafolios de inversión, midiendo a través de la beta la covarianza del precio de una acción con respecto a la totalidad del mercado accionario para conocer el grado de riesgo. Entonces, el inversionista casi de manera inmediata puede conocer si el activo o título valor es más riesgoso que el mercado o no, por tanto, la utilización de un modelo de red neuronal clasificadora, sería factible y adecuado para tal efecto, complementando el ajuste de la medición del riesgo sistemático con una adecuada escala de categorización y calificación, tomando en cuenta los criterios que subrayan las Entidades Calificadoras de Riesgo.

\subsection{Componentes básicos de la neurona}

Una neurona está compuesta básicamente por los siguientes elementos:

1. Conjunto de $n$ entradas, $u_{i}, i=1,2, n$ que suministran información del entorno. Estos datos pueden ser externos, o bien, pertenecer a las salidas de otras neuronas.

2. Conjunto de sinapsis, caracterizadas cada una por tener un peso propio $w_{j i}$. El peso $w_{j i}$ está asociado a la sinapsis que conecta la $i$-ésima neurona unidad con la $j$-ésima neurona.

3. Adicionalmente una red puede poseer un umbral, $b_{i}$, que tiene el efecto de incrementar o disminuir la entrada de la neurona. Comúnmente, los umbrales se consideran un peso más de la red, por lo cual no se hacen distinciones con respecto a los otros pesos sinápticos.

4. Un sumador que integra las entradas ponderadas con respectivos pesos y umbrales.

5. Una función de activación $f(x)$, que limita la amplitud de la salida de la neurona (Haykin, 1999). 
34 Nueva Época REMEF (The Mexican Journal of Economics and Finance)

\subsection{Componentes básicos para el funcionamiento de una red neuronal artificial}

Los aspectos fundamentales que deben ser considerados para obtener el funcionamiento correcto de una Red Neuronal Artificial son:

1. Elementos de procesamiento: Neuronas.

2. Regla de activación de los elementos.

3. Topología de interacción entre los elementos de procesamiento.

4. Regla de propagación a través de las conexiones.

5. Regla de aprendizaje.

6. Medio ambiente en el que el sistema opera (Gómez y Mendoza, 2009).

La topología de la Red Neuronal Artificial con sistema de aprendizaje de perceptrón multicapa con n neuronas de entrada, m neuronas en su capa oculta y $n$ neuronas de salida; que se utiliza en este trabajo, se representa en la Figura 1.

Figura 1. Esquema de la red neuronal artificial de perceptrón multicapa.

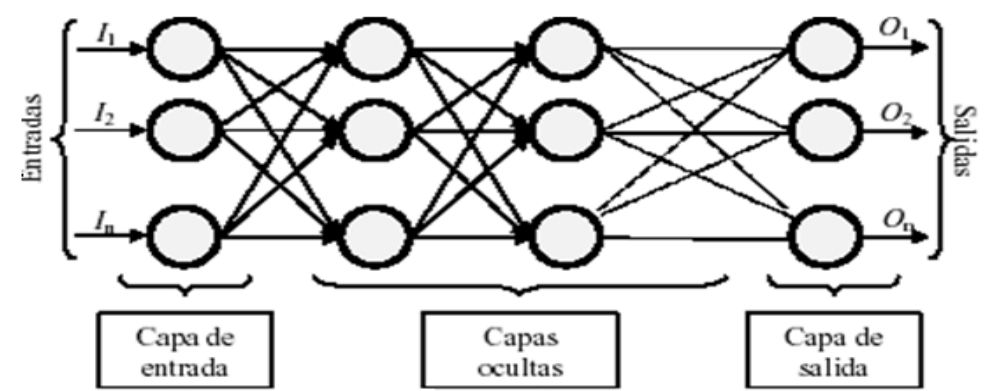

Fuente: Del Carpio (2005).

Las principales características del modelo de red, que se utiliza en este trabajo son:

1. Una red supervisada de Perceptrón Multicapa o MLP, que utiliza como función de activación la función logística; la cual es una función no lineal, creciente, acotada (tomando un intervalo entre cero y uno) y es diferenciable.

2. Se usa el perceptrón multicapa, y como función de aprendizaje la retropropagación.

3. El tipo de conexión que se aplica en la arquitectura de la RNA, es la conexión estándar que se realiza entre las capas de entrada y de salida.

4. La red de propagación hacia atrás (BP: backpropagation), se caracteriza por tener una arquitectura en niveles y conexiones entre neuronas orientadas en el mismo sentido (estrictamente hacia adelante); utilizando un mecanismo de aprendizaje supervisado, que determina cuándo la red ha aprendido correctamente (Anderson, 2007).

5. La característica útil de la RNA clasificadora, consiste en que, ante un conjunto de patrones de entrada, responde con una clasificación de las variables dadas o la información que presenten éstas, con arreglo a un conjunto finito de 
categorías o clases; que para propósitos de esta investigación las categorías del riesgo de mercado se clasifican en: bajo, medio y alto riesgo.

\subsection{Estructura de la red neuronal artificial implementada}

El objetivo principal de este trabajo es mostrar los resultados de los conjuntos de entrenamiento y de prueba de la red en la fase experimental, que contó con dos etapas de simulación. Sin embargo, para efectos de este estudio, se comentará brevemente lo realizado en la primera etapa y, posteriormente se mostrarán los resultados obtenidos en la segunda etapa de simulación, con la cual se logró un porcentaje de clasificación superior al $70 \%$ adecuado para este tipo de investigación (Gómez y Mendoza, 2009).

En la primera etapa de la simulación, para aprobar o rechazar la hipótesis nula se utilizaron como variables de entrada de la red: la tasa de interés interbancaria de equilibrio (TIIE), el tipo de cambio (peso mexicano vs. dólar americano) y los rendimientos accionarios (diferencial del precio de las acciones) en forma mensual, mostrando que los resultados obtenidos alcanzaron un porcentaje de clasificación inferior al $45 \%$; por lo que, al obtener un puntaje tan bajo se rechazó la hipótesis nula y se aceptó la hipótesis alterna.

Dado lo anterior, se decidió en la segunda etapa de la simulación aprobar la hipótesis alternativa o de trabajo, utilizando como variables de entrada: el rendimiento de mercado (rendimiento accionario), la tasa Cetes (a 91 días), tomada como la tasa libre de riesgo y la tasa de rendimiento requerida para cada empresa $\left(K_{j}\right)$, para proponer una clasificación del riesgo y poder otorgarle una escala de calificación de bajo, medio y alto; con diferentes parámetros cuantitativos, comparando los resultados con la beta del Índice de Precios y Cotizaciones, como indicador representativo del riesgo de mercado accionario mexicano. Con los resultados obtenidos en esta fase, se obtuvo un puntaje mayor al 70\%, y se aceptó la hipótesis alternativa.

El paquete utilizado para llevar a cabo las dos etapas de simulación, es el Matlab 7.0 con el módulo de redes neuronales. La estructura de la red neuronal implementada en la segunda etapa de la simulación, es una red con conexiones hacia delante (feedforward) de tres capas, comúnmente empleada en la literatura en problemas de clasificación. La red consta de una capa de entrada, una oculta y una de salida, tal como se muestra en la Figura 2.

Figura 2. Estructura de la RNA implementada, en la segunda etapa de la simulación.

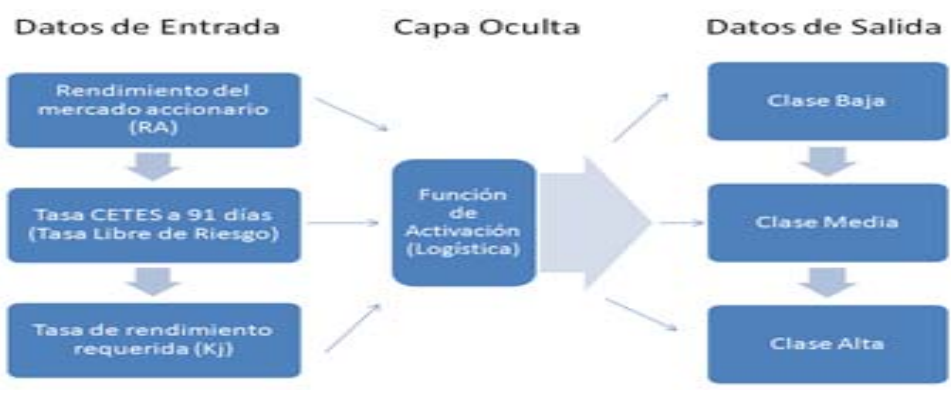

Fuente: Elaboración propia. 


\subsubsection{Capa de entrada}

La base de datos completa tomada como objeto de estudio en la primera parte de esta investigación, consta de 1296 observaciones correspondientes a las 18 acciones de las empresas más activas (con alta volatilidad) que cotizan en la Bolsa Mexicana de Valores entre los años de 2004 a 2009, utilizando datos mensuales.

Sin embargo, debido a la gran cantidad de observaciones, en la segunda parte de este trabajo se optó por reducir el conjunto de datos, empleando solamente los de cada trimestre (marzo, junio, septiembre y diciembre). Además, debido a la insuficiencia en la base de datos histórica de algunas empresas, éstas se descartaron; por lo que, el total disponible de observaciones después de este filtrado fue de 384 correspondientes a 16 compañías consideradas dentro de las más volátiles.

Cada observación consta de $n$ variables. Así que, para corroborar la selección de las observaciones empleadas se tomaron los periodos con mayor volatilidad, y la elección de éstos fue realizada primero mediante inspección visual y posteriormente comprobada por medio de estadística paramétrica, utilizando la desviación estándar de los mismos. Además, cada observación fue etiquetada empleando el valor de su beta, considerado como el indicador del grado de riesgo del mercado.

El intervalo de etiquetamiento fue determinado de tal forma que las observaciones etiquetadas se balancearan, es decir, existiera el mismo número de observaciones para cada etiqueta. Cada etiqueta representa una clase que puede ser: baja, media o alta dependiendo del nivel de riesgo de mercado, y de común acuerdo con el criterio tomado por las Entidades Calificadoras de Riesgo (ECRs). El intervalo de etiquetamiento es el siguiente:

- Clase baja: menor a una beta de 0.70

- Clase media: mayor o igual a una beta de 0.70 y menor o igual a una beta de 1.14

- Clase alta: mayor a una beta de 1.14

Obteniendo como resultado 128 observaciones de la clase baja, 129 de la clase media y 127 de la clase alta. Los intervalos fueron ajustados experimentalmente de tal forma que el número de observaciones de cada clase quedaran balanceadas, porque de otra forma el porcentaje de predicción podría verse afectado al tener una clase dominante. Las variables de entrada empleadas para alimentar la red neuronal y tratar de lograr el porcentaje de clasificación adecuado (mayor al 70\%), para el riesgo de mercado son las siguientes:

- Rendimiento accionario de las compañías tomadas como muestra (RA)

- Tasa de Cetes a 91 días, tomada como la Tasa Libre de Riesgo (CETES) $\left(K_{j}\right)$

- Tasa de rendimiento requerida por el inversionista para cada empresa

La $K_{j}$ fue calculada empleando la fórmula del Modelo de Valuación de Activos de Capital, por sus siglas en inglés CAPM: Capital Assets Pricing Model (Moyer, et al., 2005):

$$
K_{j}=\widehat{r_{f}}+\beta\left(\widehat{r_{m}}-\widehat{r_{f}}\right)
$$


Donde:

$K_{j}$ es la tasa de rendimiento requerida por los inversionistas

$\widehat{r_{f}}$ es la tasa CETES a 91 días

$\widehat{r_{m}}$ es el rendimiento esperado del mercado (rendimiento accionario)

$\beta$ es la beta de cada acción

El conjunto de datos para alimentar la red neuronal fue dividido en dos subconjuntos: de entrenamiento y de prueba; la selección de los elementos de cada subconjunto es realizada de manera aleatoria.

1) Conjunto de entrenamiento: Porcentaje de datos empleados para que la red aprenda el problema, se tomó el $80 \%$ de los ejemplos, siendo denotado como conjunto dentro de la muestra.

2) Conjunto de prueba: Datos no incorporados anteriormente, son el resto de los ejemplos que son usados para probar la capacidad de clasificación de la red, ante otros que nunca ha visto, para lo cual se utiliza el $20 \%$ restante, denotado como fuera de la muestra.

Número total de ejemplos: 384; Casos dentro de la muestra: 307 (80\%); Casos fuera de la muestra: $77(20 \%)$

\subsubsection{Capa oculta}

El número de neuronas de la capa oculta es determinado experimentalmente. La función de activación de cada neurona es la función logística.

Función Logística. Las funciones sigmoidales son un conjunto de funciones no lineales, crecientes, monótonas y acotadas. La función sigmoidal más común es la función logística definida como:

$$
f(x)=\frac{1}{1+e^{-x}}
$$

La función logística está acotada entre 0 y 1 . Los pesos sinápticos de la red fueron inicializados aleatoriamente siguiendo una distribución normal. El algoritmo de entrenamiento empleado es el algoritmo de retropropagación de gradiente conjugado escalado descrito en Moller (1993).

La red de tres capas (una de entrada, una oculta y una de salida) es la más comúnmente empleada en la literatura debido a que en el trabajo de Cybenko (1989) y Hornik (1991) se establece que toda función continúa acotada puede ser aproximada con un error ínfimo por una red de sólo una capa oculta con una función de activación de tipo sigmoidal. El postulado anterior es conocido como teorema de aproximación universal.

El algoritmo de retropropagación de gradiente conjugado escalado fue elegido debido a la rápida convergencia hacia una solución ya que tiene una complejidad computacional menor. Moller (1993), demostró que su algoritmo es más eficiente que el algoritmo de retropropagación estándar usado comúnmente con redes neuronales, además de que muestra una convergencia superlineal en la mayoría de los problemas.

El algoritmo de retropropagación de gradiente conjugado escalado se muestra a continuación:

1.Se eligen un vector de pesos $w_{l}$ y escalares $\sigma>0, \lambda_{1}>0$ y $\hat{\lambda}_{1}=0$ 
38 Nueva Época REMEF (The Mexican Journal of Economics and Finance)

$$
\text { Se establece } p=r_{1}=-E^{\prime}\left(w_{l}\right), k=1 y \text { success }=\text { true }
$$

2. Si success=true entonces se calcula la segunda derivada:

$$
\begin{gathered}
\sigma_{k}=\frac{\sigma}{\left|p_{k}\right|} \\
\frac{s_{k}=E^{\prime}\left(w_{k}+\sigma_{k} p_{k}\right)-E^{\prime}\left(w_{k}\right)}{\sigma_{k}} \\
\delta_{k}=p_{k}^{T} s_{k}
\end{gathered}
$$

3. Se escala $s_{k}$ :

$$
\begin{gathered}
s_{k}=s_{k}+\left(\lambda_{k}-\bar{\lambda}_{k}\right) p_{k} \\
\delta_{k}=\delta_{k}+\left(\lambda_{k}-\bar{\lambda}_{k}\right)\left|p_{k}\right|^{2}
\end{gathered}
$$

4. Si $\delta_{k} \leq 0$ entonces hacer la matriz Hessiana definida positiva:

$$
\begin{gathered}
s_{k}=s_{k}+\left(\lambda_{k}-2 \frac{\delta_{k}}{\left|p_{k}\right|}\right) p_{k} \\
\bar{\lambda}_{k}=2\left(\lambda_{k}-\frac{\delta_{k}}{\left|p_{k}\right|^{2}}\right) \\
\delta_{k}=-\delta_{k}+\lambda_{k}\left|p_{k}\right|^{2} \\
\lambda_{k}=\bar{\lambda}_{k}
\end{gathered}
$$

5. Se calcula el tamaño del paso:

$$
\begin{gathered}
\mu_{k}=p_{k}^{T} r_{k} \\
\alpha_{k}=\frac{\mu_{k}}{\delta_{k}}
\end{gathered}
$$

6. Se calcula el parámetro de comparación:

$$
\Delta_{k}=\frac{2 \delta_{k}\left[E\left(w_{k}\right)-E\left(w_{k}+\alpha_{k} p_{k}\right)\right]}{\mu_{k}^{2}}
$$

7. Si $\Delta_{k} \geq 0$ entonces una reducción del error puede ser hecha:

$$
\begin{gathered}
w_{k+1}=w_{k}+\alpha_{k} p_{k} \\
r_{k+1}=-E^{\prime}\left(w_{k+1}\right) \\
\bar{\lambda}_{k}=0 \\
\text { success }=\text { true }
\end{gathered}
$$

8. Si $k \bmod N=0$ entonces reinicia el algoritmo:

$$
p_{k+1}=r_{k+1}
$$


de lo contrario se crea una nueva dirección del conjugado:

$$
\begin{gathered}
\beta_{k}=\frac{\left|r_{k+1}\right|^{2}-r_{k+1} r_{k}}{\mu_{k}} \\
p_{k+1}=r_{k+1}+\beta_{k} p_{k}
\end{gathered}
$$

9. Si $\Delta_{k} \geq 0.75$ entonces se reduce el parámetro de escalamiento:

$$
\lambda_{k}=\frac{1}{2} \lambda_{k}
$$

de lo contrario no es posible reducir el error:

$$
\begin{gathered}
\bar{\lambda}_{k}=\lambda_{k} \\
\text { success }=\text { false }
\end{gathered}
$$

10. Si $\Delta_{k} \leq 0.25$ entonces se incremente el parámetro de escalamiento:

$$
\lambda_{k}=4 \lambda_{k}
$$

11 Si la dirección del descenso de gradiente $r_{k} \neq 0$ entonces se establece

$$
k=k+1 \text { e ir a } 2
$$

12. De lo contrario terminar y regresar $w(k+1)$ como el mínimo deseado donde: $p_{k}$ es un subconjunto de un sistema conjugado; $E($.$) es una función de$ error global (MSE); $E^{\prime}($.$) es la primera derivada de la función de error E($.$) .$

Se realizaron múltiples experimentos para determinar el número de neuronas de la capa oculta. La búsqueda del número de neuronas adecuado para el problema de clasificación en cuestión, fue efectuada en un intervalo de 15 a 20 neuronas, formando un total de 5 redes neuronales.

Se llevaron a cabo 20 experimentos por cada red neuronal. Cada experimento es realizado cambiando los pesos sinápticos aleatorios iniciales de cada red neuronal. Además, de variar los tamaños del conjunto de entrenamiento en 70,75, $80 \mathrm{u} 85 \%$, es decir, el conjunto de entrenamiento representa ese porcentaje del total de observaciones disponibles, formando un total de 20 combinaciones.

Combinaciones $=$ \# de configuración en la capa oculta $\mathrm{x}$.

(Diferentes tamaños del grupo de entrenamiento)

Los promedios de error MSE (sobre los 20 experimentos) para cada red neuronal del conjunto de entrenamiento se muestran en la Tabla 1. 
40 Nueva Época REMEF (The Mexican Journal of Economics and Finance)

Tabla 1. Promedios de error [MSE] del conjunto de entrenamiento de las redes neuronales. El promedio de error (MSE) deseado es cero, mientras que el error máximo es 1.

\begin{tabular}{|c|c|c|c|}
\hline Nodos Capa Oculta & Tamaño Conjunto de Entrenamiento & Promedio de Error (MSE) & Desviación Estándar \\
\hline \multirow{3}{*}{15} & $\begin{array}{l}70 \% \\
75 \%\end{array}$ & $\begin{array}{l}0.33364312 \\
0.32569444\end{array}$ & $\begin{array}{l}0.27471056 \\
0.28025286\end{array}$ \\
\hline & $80 \%$ & 0.327855016 & 0.28365945 \\
\hline & $\begin{array}{l}85 \% \\
70 \%\end{array}$ & $\begin{array}{l}0.32684049 \\
0.39609665\end{array}$ & $\begin{array}{l}0.28726380 \\
0.26009151\end{array}$ \\
\hline \multirow{3}{*}{16} & $75 \%$ & 0.37239583 & 0.27880426 \\
\hline & $80 \%$ & 0.36954397 & 0.28770251 \\
\hline & $85 \%$ & 0.36533742 & 0.28483524 \\
\hline \multirow{4}{*}{17} & $70 \%$ & 0.39219331 & 0.23681348 \\
\hline & $75 \%$ & 0.39027778 & 0.24186065 \\
\hline & $80 \%$ & 0.37703583 & 0.25762543 \\
\hline & $85 \%$ & 0.37361963 & 0.25688348 \\
\hline \multirow{4}{*}{18} & $70 \%$ & 0.28438662 & 0.23667046 \\
\hline & $75 \%$ & 0.26059028 & 0.24986608 \\
\hline & $80 \%$ & 0.23664495 & 0.24777822 \\
\hline & $85 \%$ & 0.23788344 & 0.24861102 \\
\hline \multirow{4}{*}{19} & $70 \%$ & 0.48977695 & 0.2306687 \\
\hline & $75 \%$ & 0.45104167 & 0.23009833 \\
\hline & $80 \%$ & 0.45114007 & 0.23843448 \\
\hline & $85 \%$ & 0.45122699 & 0.24103853 \\
\hline \multirow{4}{*}{20} & $70 \%$ & 0.41914498 & 0.2125922 \\
\hline & $75 \%$ & 0.41979167 & 0.21377697 \\
\hline & $80 \%$ & 0.40977199 & 0.21765345 \\
\hline & $85 \%$ & 0.4101227 & 0.2191977 \\
\hline
\end{tabular}

Fuente: Elaboración propia.

La red que obtuvo el menor error durante el entrenamiento fue la red neuronal de 18 nodos en la capa oculta, con un $80 \%$ (307 observaciones) del total de las observaciones empleadas. La Tabla 2 representa la matriz de confusión del promedio de los 20 experimentos de esa red sobre el conjunto de entrenamiento.

Tabla 2. Matriz de confusión de la clasificación del conjunto de entrenamiento.

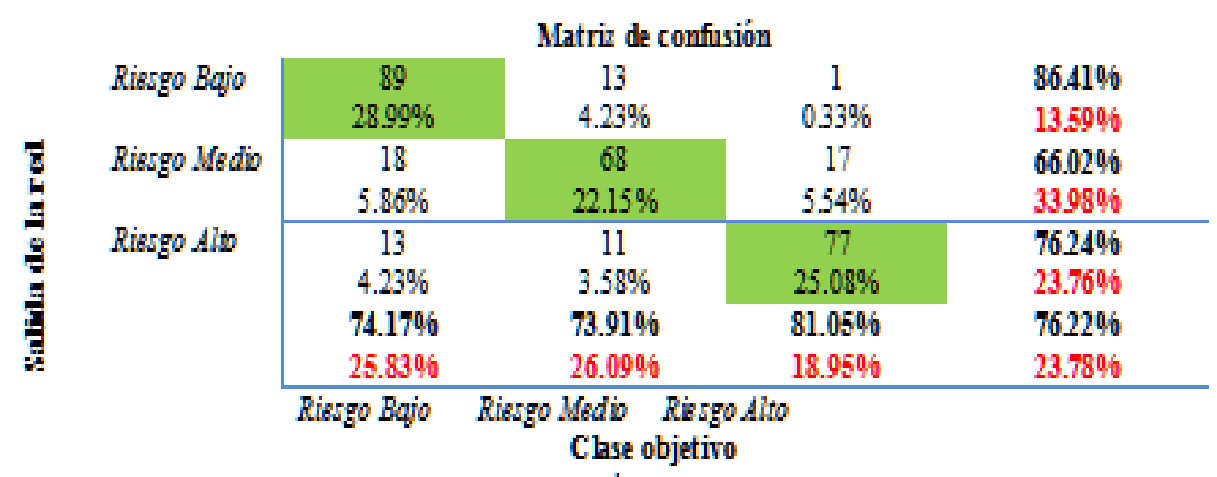

Fuente: Elaboración propia. 
La determinación de los nodos es realizada experimentalmente. Se prueban diferentes números de nodos en la capa oculta con el fin de determinar cuál es la mejor configuración para el problema en cuestión. Debe tenerse en cuenta, que si el número de nodos es muy alto se corre el riesgo de sobreajustar la red a los datos dados perdiendo generalización. La generalización se refiere a la capacidad de la red de poder predecir una clase dado un valor que no forma parte de la muestra de entrenamiento (Haykin, 1999).

El error de cada experimento es determinado mediante el error cuadrático medio ó mean squared error (MSE, por sus siglas en inglés). El MSE es una medida de desempeño empleada comúnmente al evaluar la eficacia de clasificación de una red neuronal. Mide la eficacia de la red de acuerdo a la media de los errores cuadrados. El error es obtenido mediante la siguiente fórmula:

$$
e=x-\hat{x}
$$

Dónde:

$x$ es el valor conocido, en este caso la clasificación dada a priori de la observación durante el etiquetamiento.

$\hat{x}$ es el valor dado por la red, la clasificación a la que la red cree pertenece la observación. Entonces MSE se define matemáticamente como:

$$
M S E=\sum_{i=1}^{n}\left(e_{i}\right)^{2}
$$

Dónde:

$n$ es el número de observaciones total clasificadas en la muestra (conjunto de prueba o de entrenamiento o ambos).

En la Tabla 3, se muestra la tabla de error de los experimentos hechos con la red neuronal de 18 nodos en la capa oculta y un conjunto de prueba formado por el $20 \%$ de observaciones del total de datos disponibles. Los conjuntos de entrenamiento y de prueba son mutuamente excluyentes.

\begin{tabular}{|c|c|}
\hline No. Exp=rimento & Emor (NISE) \\
\hline 1 & $0.0129 \mathrm{erol}$ \\
\hline 2 & 0.44155844 \\
\hline 3 & 0.07792200 \\
\hline 4 & 0.00000000 \\
\hline 5 & 0.07792208 \\
\hline 6 & 0. 74025974 \\
\hline 7 & 0.05194805 \\
\hline $\mathrm{E}$ & o. $05194 \mathrm{gos}$ \\
\hline 9 & 0.36363636 \\
\hline 10 & 0.57142857 \\
\hline 11 & $0.02597+00$ \\
\hline 12 & 0.40259740 \\
\hline 13 & $0.02597+109$ \\
\hline $1 \div$ & 0.06493506 \\
\hline 15 & 0.00000009 \\
\hline 16 & $0.6753246 \mathrm{~B}$ \\
\hline 17 & $0.0779220 \mathrm{a}$ \\
\hline $1 \mathrm{~B}$ & 0.76623377 \\
\hline 19 & 0.07792208 \\
\hline 20 & $0 .+1558+42$ \\
\hline 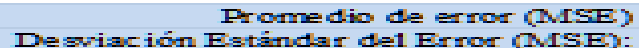 & $\begin{array}{l}0255104005 \\
025770384\end{array}$ \\
\hline
\end{tabular}

Tabla 3. Promedios de error con el conjunto de prueba. 
Fuente: Elaboración propia.

La red con la configuración antes mencionada (cada red representa un experimento de los 20 realizados) fue empleada para la clasificación del conjunto de prueba, obteniendo un promedio de error sobre los 20 experimentos de $25.52 \%$ con una desviación estándar promedio de 25.78. Teniendo en cuenta que el promedio de error es la suma de los $20 \mathrm{MSE}$ (uno por cada experimento), la desviación es con respecto al promedio y el promedio de error (MSE) es lo mismo que la media.

Por último, la Tabla 4 representa la matriz de confusión del promedio de los 20 experimentos de la red de 18 nodos, sobre el conjunto de prueba.

Tabla 4. Matriz de confusión de la clasificación del conjunto de prueba.

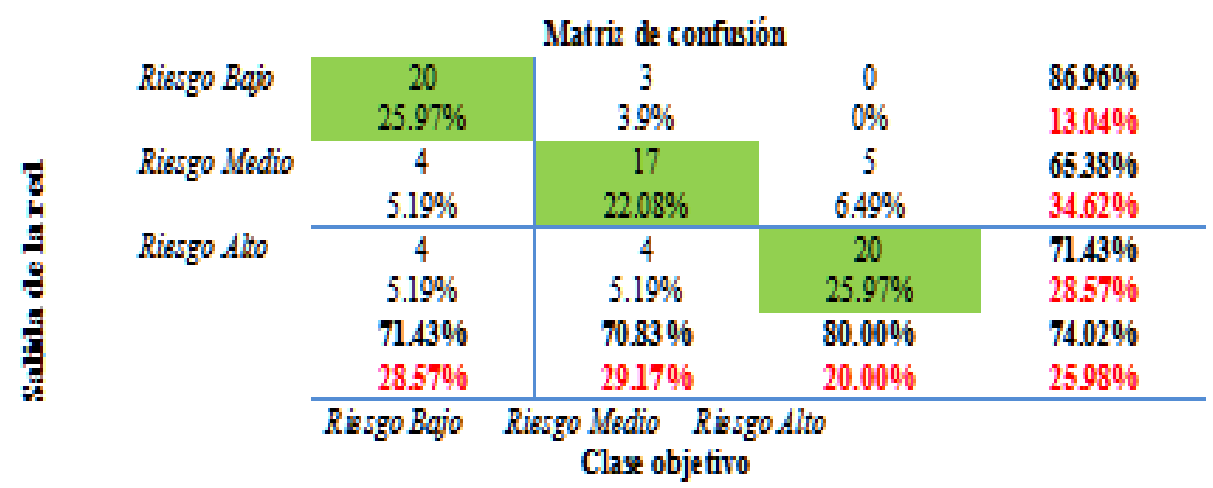

Fuente: Elaboración propia.

\subsubsection{Resultados de la capa de salida} y alto.

Objetivo: Determinación de las clases del riesgo de mercado en bajo, medio

La función de activación $f(x)$ es la que determina la salida de la red neuronal y limita la amplitud de la salida de la neurona. La salida está definida como:

$$
y_{i}=f\left(\sum_{i=1}^{n} w_{j i} u_{i}+b_{j}\right)
$$

Obteniendo como resultados globales de clasificación, en las fases de entrenamiento y prueba los siguientes:

Número de ejemplos clase 3 (riesgo bajo): 128 (beta menor a 0.70)

Número de ejemplos clase 2 (riesgo medio): 129 (beta de 0.70 y menor o igual a una beta de 1.14)

Número de ejemplos clase 1 (riesgo alto): 127 (beta mayor a 1.14)

\section{Análisis e interpretación de los datos}

La base de datos ya depurada para la segunda fase de la simulación, cuenta con 384 observaciones correspondientes a las 16 acciones de las empresas más 
activas o volátiles que cotizan en la Bolsa Mexicana de Valores en periodos trimestrales entre los años de 2004 a 2009. El diseño de la investigación es experimental, ya que se fundamenta en un enfoque cuantitativo, y se centra en la validez de los datos para el cálculo y la medición del riesgo de mercado aplicando una RNA clasificadora.

El conjunto de datos empleados para la calificación y clasificación del riesgo de mercado, corresponden a la valuación trimestral de las variables de entrada, y cada conjunto consta de 4 ejemplos por cada empresa en un periodo de 6 años. El total de observaciones disponibles utilizadas en la segunda fase de la simulación, fue de 384 ejemplos correspondientes a 16 empresas. Cada ejemplo consta de las siguientes variables: rendimiento accionario (RA), tasa de Cetes a 91 días (CETES) tomada como la tasa libre de riesgo y la tasa de rendimiento requerida para cada empresa $\left(K_{j}\right)$.

Los resultados de salida en las fases de entrenamiento y prueba, clasificaron al riesgo de mercado como bajo, medio y alto. La muestra consta de 128 ejemplos de riesgo bajo, 129 ejemplos de riesgo medio y 127 correspondientes a riesgo alto.

El mejor resultado de las simulaciones efectuadas en el subconjunto de entrenamiento de los casos (suma diagonal de la matriz de confusión), señala una efectividad de clasificación para el conjunto dentro de la muestra de $76.22 \%$ de ejemplos correctamente clasificados. Mientras que, para las clases objetivo, se obtuvieron los siguientes porcentajes de ejemplos correctamente clasificados: $28.99 \%$ de riesgo bajo, $22.15 \%$ de riesgo medio y $25.08 \%$ de riesgo alto, tal como se observa en la matriz de confusión de la Tabla 2.

El mejor resultado de las simulaciones efectuadas en el subconjunto de prueba de los casos (suma diagonal de la matriz de confusión), señala una efectividad de clasificación para el conjunto fuera de la muestra de $74.02 \%$ de ejemplos correctamente clasificados. Mientras que, para las clases objetivo, se obtuvieron los siguientes porcentajes de ejemplos correctamente clasificados: $25.97 \%$ de riesgo bajo, $22.08 \%$ de riesgo medio y $25.97 \%$ de riesgo alto, tal como se observa en la matriz de confusión de la Tabla 4.

\section{Comparación de los resultados de clasificación del riesgo de mercado resultantes de la red neuronal con los de las principales entidades calificadoras de riesgo en México.}

Todas las calificadoras de riesgo en el mundo tienen una serie de indicadores o notas que definen, el sistema de escalas para la medición de diferentes tipos de riesgo, pero sobre todo del riesgo crediticio, dentro del cual está implícito el riesgo de mercado de las empresas que cotizan en los diferentes mercados. En términos generales una calificación es una opinión especializada e independiente, que expresa una entidad especializada y autorizada por los mercados bursátiles, sobre la capacidad y condiciones de una emisora para cumplir con sus obligaciones y emisiones, analizando las características de estos créditos e inversiones de capital que garantizan o respaldan estos instrumentos (S\&P, 2009).

El $75 \%$ de las empresas tomadas como objeto de estudio en la presente investigación, fueron calificadas por Standard \& Poors de México, y de acuerdo a esta entidad se consultaron las calificaciones emitidas al primer trimestre 
del 2010, que obtuvieron las 16 empresas más bursátiles de la BMV, tomando como fecha de corte Diciembre de 2009, considerando una escala de calificación de manera generalizada y de común acuerdo son los criterios del mapeo de calificaciones y grados de riesgo para esquemas de bursatilización e inversión a largo plazo de las escalas globales y locales que utilizan las principales Entidades Calificadoras de Riesgo en México: Standard \& Poors, Fitch y Moodys, para efectuar el comparativo y así ajustar la medición del riesgo de las emisoras seleccionadas.

La interpretación y análisis de la información de salida de la red, clasificó al riesgo de mercado como bajo, medio y alto. Los resultados se compararon con la escala de calificación de las principales Entidades Calificadoras de Riesgo (ECR) en nuestro país como la S\&P, Fitch y Moody's de México. Es importante recalcar que, la categorización de las clases objetivo que se establecieron para que la red clasificara al riesgo de mercado, fue tomando en cuenta solamente variables de carácter cuantitativo, por lo que, al realizar la comparación de los resultados de clasificación de la red, con los de las entidades calificadoras, no se consideran los aspectos cualitativos que también inciden en el mercado de las acciones, debido a que los datos de las variables de entrada son numéricos, por lo que se asume cierto grado de sesgo en la comparación.

Esta situación es conveniente comentarla, porque a pesar de que la calificación de riesgo de mercado, es realizada por agencias calificadoras de gran prestigio como la S\&P, Fitch y Moody's en la escala de calificación que utilizan, no se puede apreciar en forma significativa una distinción o separación que defina perfectamente las escalas de calificación del tipo de riesgo que midieron y calificaron; porque, dependiendo de las características inherentes al título valor de que se trate, se mide y califica el riesgo financiero, de crédito y por ende el riesgo de mercado, con variables cualitativas y cuantitativas.

Una vez que se tomaron las clasificaciones y calificaciones del grado de riesgo de las instituciones autorizadas en México para calificar el riesgo de crédito, el cual contiene implícito el riesgo de mercado, se continuó con la elaboración de un resumen que se muestra en la Tabla 5 sobre los resultados obtenidos en la fase de prueba del proceso de simulación de la RNA que muestra la categorización de las etiquetas o valores de salida en la segunda etapa de simulación, en donde se utilizó el conjunto de datos de prueba o validación con datos que la red nunca había visto, efectuándose un total de 20 experimentos. Los resultados de cada experimento utilizando el conjunto de prueba, se analizaron por cada emisora para validar que realmente la red aprendió a categorizar los datos y con qué porcentaje de aciertos en cada emisora, con relación a las variables independientes (valores de entrada que se suministraron a la red), y con base en las etiquetas y valores de las clases de riesgo de mercado, definidas por la beta de cada emisora, consideradas para determinar el número y el nombre de las clases objetivo: Clase 3: Riesgo bajo; Clase 2: Riesgo medio y Clase 1: Riesgo alto (variables de salida), tal como se observa en la Tabla 5. 
Tabla 5. Datos utilizados para definir la escala de clasificación objetivo de la red con el conjunto de prueba.

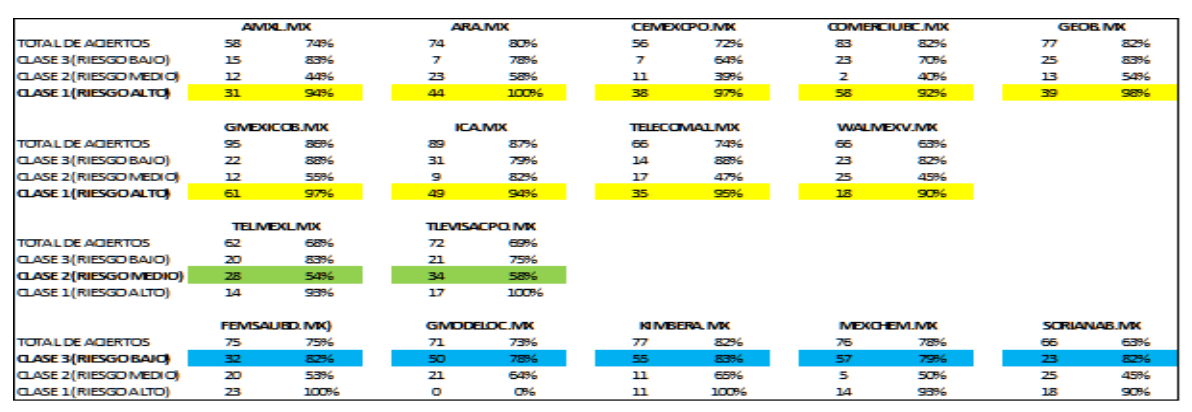

Fuente: Elaboración propia.

Para ilustrar cómo se determinó la clasificación y las escalas de riesgo de la RNA para compararlas con los resultados de las ECR, se tomó en cuenta el mapeo de calificaciones que la Comisión Nacional Bancaria y de Valores (CNBV), para verificar las escalas de calificación del grado de inversión, que publicó la Secretaría de Hacienda y Crédito Público (SHCP) en el Diario Oficial de la Federación el viernes 09 de Abril del 2010: "Resolución por la que se modifican las disposiciones de carácter general aplicables a las instituciones de crédito" (DOF, 2010).

Al analizar y comparar los resultados de las escalas de categorización de la red, con los grados de bursatilización e inversión utilizando el mapeo de calificaciones que utiliza la CNBV, se observa que el mapeo recurre al método estándar para calificar el grado de bursatilización e inversión. Dado que el riesgo de mercado está implícito el riesgo de crédito o de inversión, "cuando una institución calificadora, otorgue una calificación, según la escala y el tipo de moneda que corresponda, las instituciones deberán ajustarse a la Matriz de Calificaciones y Grados de Riesgo a Largo Plazo Escalas Globales y Locales, para asociar la calificación asignada con el grado de riesgo" (DOF, 2010).

Sin embargo, en un esfuerzo por homogeneizar y unificar el proceso de calificación del grado de riesgo de crédito y la escala del mismo, la Secretaría de Hacienda y Crédito Público (SHCP), recientemente publicó la 25. "Resolución por la que se modifican las disposiciones de carácter general aplicables a las instituciones de crédito" (DOF, 2010), en donde figuran especialmente los Anexos 1-B y 1-G que muestran el mapeo de calificaciones y grados de riesgo para esquemas de bursatilización e inversión, considerando las calificaciones y los grados de riesgo a corto y largo plazo, tomando en cuenta las escalas globales y locales que utilizan principalmente Standard \& Poors, Moodys y Fitch en México.

La comparación de los resultados de la clasificación y calificación que la red neuronal otorgó al riesgo de mercado, con los que muestran las principales Entidades Calificadoras de Riesgo en México, se presentan en el comparativo de la Tabla 6, el cual resulta significativo para establecer un efecto neto sobre el grado y la escala de riesgo que emiten las agencias calificadoras y la escala de riesgo de mercado que emitió la red neuronal, para establecer un parámetro 
que ayude al inversionista como guía en la toma de decisiones, en función de las operaciones de inversión o financiamiento que realice en el mercado accionario mexicano.

Tabla 6. Comparativo que muestra los grados de riesgo de crédito e inversión con la escala de clasificación del riesgo de mercado.

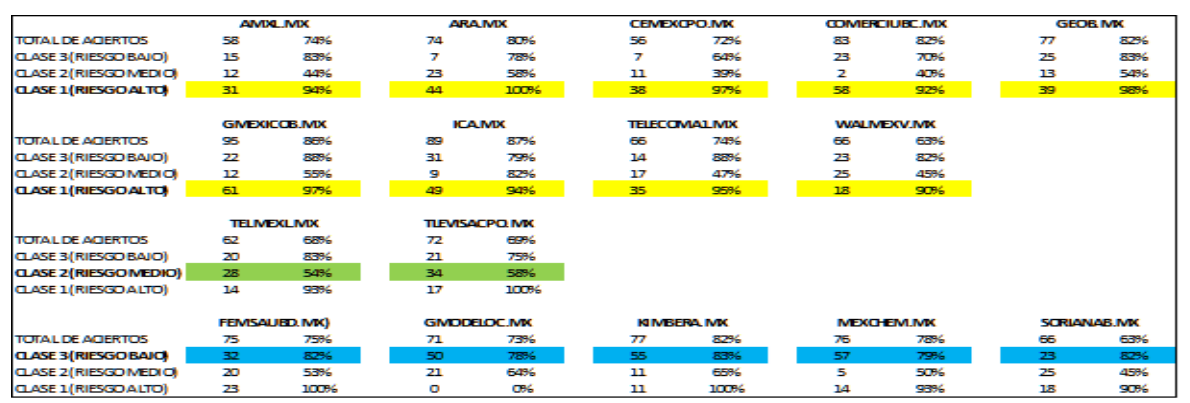

Fuente: Elaboración propia.

\section{Conclusiones acerca de los resultados sobre la calificación del riesgo}

Considerando que el periodo de estudio abarcó desde el 2004 hasta el 2009, para desarrollar el tema central del trabajo presentado, y de conformidad con el segundo objetivo específico que se planteó para ser investigado y, con ello ratificar la validez de la hipótesis de trabajo (H1); se elaboró el cuadro comparativo para:

1. Mostrar los grados de riesgo de crédito e inversión que utilizan las Entidades Calificadoras de Riesgo en comparación con la escala de clasificación del riesgo de mercado que obtuvo la red neural clasificadora, y

2. Medir la relación entre ambas escalas, como guía para la toma de decisiones, razón por la cual se desprenden las siguientes conclusiones:

a) Si el grado de inversión es 1, entonces se considera que la emisora tiene un riesgo de inversión sumamente bajo. Es decir, presenta una capacidad extremadamente fuerte para cumplir con sus compromisos financieros; y que en forma conjunta con los resultados de clasificación de la red para el riesgo de mercado, si la RNA la clasificó en la clase 1, (riesgo alto); entonces la combinación riesgo de crédito vs riesgo de mercado tiene un efecto altamente positivo, porque el inversionista (tomador de decisiones), tendrá la máxima certeza en su elección, debido a que la empresa tiene una muy fuerte solidez financiera; premisa que se ve reflejada en un aumento considerable de la bursatilidad de la acción, generando alzas considerables en los precios y por ende en las tasas de rendimiento. El riesgo del mercado se considera extremadamente alto; ya que la relación riesgo vs. rendimiento se maximiza: a mayor riesgo, mayor rendimiento. La beta de la acción es mayor a 1 tiende a fluctuar más que el mercado. El valor de la beta que la RNA utilizó para etiquetar el riesgo sistemático como alto fue una beta mayor a 1.14.

b) El 19\% de las 16 emisoras más activas que conforman la muestra, reflejan una relación altamente positiva, éstas son: América Móvil, Walmart y Grupo Carso Telecom. 
c) Si el grado de inversión es 3 ó 4, entonces se considera que la emisora tiene un riesgo de inversión moderado. Es decir, presenta una capacidad fuerte para cumplir con sus compromisos financieros. Además, es considerada como poseedora de características especulativas importantes; y que en forma conjunta con los resultados de clasificación de la red para el riesgo de mercado, si la RNA la clasificó en la clase 1, (riesgo alto), entonces la combinación riesgo de crédito vs riesgo de mercado tiene un efecto positivo moderado, porque el inversionista tendrá la certeza sobre su elección, porque la empresa tiene fuerte solidez financiera; premisa que se ve reflejada por una constante bursatilidad de la acción con tendencia a la alza. Por lo tanto, el riesgo de mercado se considera alto, con una beta mayor a 1 .

d) El $31 \%$ de las 16 emisoras más activas que conforman la muestra mantiene un efecto positivo moderado, tal es el caso de: Cemex, Grupo México, Empresas Ica, Consorcio Ara, Corporación Geo.

e) Si el grado de inversión es 1 ó 2 , entonces se considera que la emisora tiene un riesgo de inversión bajo. Es decir, presenta una capacidad muy fuerte para cumplir con sus compromisos financieros; y que en forma conjunta con los resultados de clasificación de la red para el riesgo de mercado, si la RNA la calificó en la clase 2 (riesgo medio), entonces la combinación riesgo de crédito vs riesgo de mercado tiene un efecto positivo moderado, ya que el inversionista tendrá la certeza de que la empresa tiene fuerte solidez financiera, pero una bursatilidad paulatina. Por lo tanto, el riesgo de mercado se considera moderado, es decir, la acción seguirá la misma tendencia que la del mercado y su beta será muy aproximada o igual a 1 . El intervalo de la beta que la RNA utilizó para etiquetar el riesgo como medio, fue una beta mayor o igual a 0.70 y menor o igual a 1.14.

f) El $13 \%$ de las 16 emisoras más activas que conforman la muestra mantiene un efecto positivo moderado, tal es el caso de Telmex y Grupo Televisa.

g) Si el grado de inversión es 1 ó 2 , entonces se considera que la emisora tiene un riesgo de inversión bajo. Es decir, presenta una muy fuerte capacidad para cumplir con sus compromisos financieros; y que en forma conjunta con los resultados de clasificación de la red para el riesgo de mercado, si la RNA la calificó en la clase 3 (riesgo bajo), entonces la combinación riesgo de crédito vs riesgo de mercado tiene un efecto neutro ó adverso, ya que el inversionista, tendrá la certeza de que la empresa tiene fuerte solidez financiera, pero una bursatilidad con poco movimiento. Por lo tanto, la decisión de inversión dependerá del nivel de riesgo y el rendimiento esperado que el inversionista deseé como mínimo, ya que el riesgo de mercado se considera bajo. La acción con una beta menor a 1 tiende a tener un menor movimiento que el mercado en términos porcentuales, por lo que, la tasa de rendimiento esperada también es baja, debido a la poca variabilidad de los precios accionarios.

h) El $31 \%$ de las 16 emisoras más activas que conforman la muestra mantiene un efecto neutro o adverso, tal es el caso de Mexichem, Fomento Económico Mexicano, Soriana, Kimberly Clark y Grupo Modelo.

i) Finalmente, si el grado de inversión es 5 , entonces se considera que la emisora tiene un riesgo de crédito bastante alto. Es decir, cuenta con una mínima capacidad de pago, pero ésta es muy variable y susceptible de 
debilitarse ante posibles cambios en los emisores del sector al que pertenece o en la economía pudiendo incurrirse en la pérdida del capital e intereses. Las emisoras calificadas en estas categorías son consideradas como poseedoras de características especulativas importantes; y que en forma conjunta con los resultados de clasificación de la red para el riesgo de mercado, si la RNA la clasificó en la clase 1, (riesgo alto), entonces la combinación riesgo de crédito vs riesgo de mercado tiene un efecto negativo adverso, porque el inversionista tendrá un nivel de certeza muy bajo o quizá nulo para tomar su decisión, debido a que la empresa no tiene solidez financiera; premisa que se ve reflejada por una alta bursatilidad de la acción, pero con una tendencia no definida, que puede tener cambios muy bruscos a la alza o a la baja en periodos muy cortos. Por esta razón, el riesgo de mercado se considera alto con una beta mayor a 1; pero dependiendo de la posición en la que se encuentre el inversor, podrá tener títulos valor o portafolios que le generen mucho riesgo y poco rendimiento, con relación a otros que tienen el mismo porcentaje de riesgo, pero con mayores rendimientos.

La alta bursatilidad o variabilidad que se presenta en los precios accionarios y por consecuencia en los rendimientos, aún cuando la empresa no genera suficientes fondos para el pago de su deuda; se explica porque la emisora efectúa muy a menudo una recompra y reventa de sus propias acciones (por lo general acciones de tesorería), para darle movilidad al mercado en el que opera; y de esta forma, provoca deliberadamente que el grado de bursatilidad y rentabilidad aumente para adelantarse y ganarle al mercado.

j) El $6 \%$ de las 16 emisoras más activas que conforman la muestra mantiene un efecto negativo adverso, tal es el caso de Controladora Comercial Mexicana.

Por lo tanto, en base al análisis efectuado se concluye que la calificación que emiten las Entidades Calificadoras de Riesgo, se basan principalmente en el riesgo crediticio, y que los estudios que realizan para analizarlo son fundamentales en el desarrollo y madurez del mercado accionario mexicano, porque se asegura la promoción de la transparencia en la información y la cultura de la medición del riesgo.

Además, las compañías que aceptan someterse a un proceso de calificación pueden ampliar con mayor flexibilidad sus fuentes de financiamiento y por ende, tener mayor crecimiento en sus flujos de efectivo para seguir cotizando en la Bolsa Mexicana de Valores, reducir sus costos de endeudamiento, mejorar la relación con proveedores, obtener significativo posicionamiento a nivel global para extender sus operaciones de mercado, entre muchas otras ventajas.

Para concluir, cabe mencionar que la mayoría de las emisoras presentan las ventajas que se enumeraron con anterioridad, lo cual resulta lógico si se toma en cuenta que al ser consideradas como las más activas o bursátiles, por lo general, la relación entre el riesgo y el rendimiento esperado se maximiza al mostrar una correlación positiva perfecta con la tendencia que sigue el mercado, asumiendo condiciones de normalidad, crecimiento y dinamismo en la economía mexicana. 


\subsection{Originalidad, impacto y alcance de la investigación}

La contribución original de este estudio consiste en que no hay antecedentes sobre trabajos o investigaciones en la medición del riesgo de mercado en México, aplicándose un modelo de Red Neuronal Artificial Clasificadora para incentivar la búsqueda de nuevos modelos en su calificación; solo algunos estudios se han enfocado a la medición de la rentabilidad de los activos, el pronóstico de la calificación crediticia y la solvencia empresarial.

Se apertura una nueva línea para impulsar y apoyar la investigación económico-financiera, mostrando un método inédito para el ajuste de la medición del riesgo en el mercado bursátil nacional, ya que al utilizar las redes neuronales como herramientas de clasificación del riesgo de mercado, los agentes económicos podrán contar con otra alternativa que les oriente en el análisis de sus inversiones y la estructura de su capital para maximizar sus rendimientos, logrando una mejor toma de decisiones.

Finalmente, con la metodología implementada se muestra la importancia de las redes neurales artificiales como una herramienta adicional para medir y clasificar al riesgo sistémico del mercado accionario mexicano, pudiéndose aplicar también a otros mercados, porque así lo permiten las características del modelo de red neuronal utilizado y la naturaleza de los datos suministrados, entendiendo que los datos de entrada que se suministraron a la red fueron tomados del Modelo de Valuación de Activos de Capital y los datos de salida de un parámetro clásico y bien fundamentado por la teoría financiera clásica para medir la sensibilidad al riesgo de mercado como lo es la beta.

En base a lo anterior, el algoritmo de la red diseñado para los propósitos de esta investigación se fortalece al combinar un modelo eminentemente financiero con uno matemático y de inteligencia artificial como es el caso de las redes neuronales artificiales; sobre todo si se toma en cuenta que la muestra utilizada está conformada por datos en épocas de crisis financieras recientes tales como la del 2004 que impactó fuertemente en los indicadores globales de la economía nacional, pero sobre todo la crisis económica del 2008 de alcance internacional que golpeó duramente a los países desarrollados como Estados Unidos, entre otros.

\section{Bibliografía}

Anderson, J. (2007). Redes Neurales. Grupo Editor Alfa Omega, pp. 258-260.

Atiya, A. (2001). Bankruptcy Prediction for Credit Risk Using Neural Networks: A Survey and New Results. IEEE Transactions on Neural Networks, 12 (4), pp. 929-935.

Banco de México. (2005). Definiciones Básicas de Riesgos. Noviembre, 1-9.

Carmona Vega Esther Guadalupe y González Garzón Aura María. (2011) Ajuste de la calificación del riesgo de mercado de las empresas más activas que cotizan en la Bolsa Mexicana de Valores, con la implementación de una red neuronal artificial clasificadora. Tesis de Doctorado, Universidad Popular Autónoma del Estado de Puebla. Segundo Lugar del Premio Nacional Bolsa Mexicana de Valores en la categoría de Investigación.

Cleveland, W. S. (1979). Robust Locally Weighted Regression and Smoothing Plots. Journal of the American Statistical Association, 74, 829-836.

Corredor, P. y Santamaría, R. (2004). Forecasting Volatility in the Spanish Option Market. Applied Financial Economics, 14, pp. 1-11.

Cruz, I. (2007). Pronósticos en el Mercado de Derivados Utilizando Redes Neuronales y Modelos ARIMA: Una Aplicación a los Cetes de 91 días en el MexDer. (Tesis 
de Maestría, Facultad de Contaduría y Administración de la Universidad Nacional Autónoma de México), México, D. F. Recuperado en www.mexder.com.mx/.../mexder/.../ Pronósticos en el mercado de derivados utilizando redes neuronales y modelos ARIMA.pdf

Cybenko, G. (1989). Approximations by Superpositions of Sigmoidal Functions. Mathematics of Control, Signals, and Systems, 2 (4), pp. 303-314.

Deboeck, G. J. (1994). Trading on the Edge: Neural, Genetic and Fuzzy Systems for Chaotic Financial Markets. New York: John Wiley \& Sons.

Del Carpio, J. (2005). Las Redes Neuronales Artificiales en las Finanzas. Industrial Data. Universidad Nacional Mayor de San Marcos, Lima, Perú, 8 (002), pp. 1-7.

Diario Oficial de la Federación. (2010). 25 Resolución por la que se Modifican las Disposiciones de Carácter General Aplicables a las Instituciones de Crédito. En DOF el 9 de Abril del 2010.

Espinosa, C. (2005). El Mundo de la Predicción: Redes Neuronales, un ejemplo. Universidad de Santiago de Chile. Agosto, pp. 1-3.

Fernández, R. F. y Acosta, G. E. (2001). Predicción del Fracaso Empresarial Mediante el Uso de Algoritmos Genéticos. (Tesis Doctoral, Universidad de Las Palmas de Gran Canaria, Departamento de Métodos Cuantitativos en Economía y Gestión, Campus de Tafira). Las Palmas de Gran Canaria, España. Recuperado en www.revecap.com/encuentros/anteriores/xeea/trabajos/a/.../127.pdf

Gómez, P. y Mendoza, A. (2009). Herramientas para el Pronóstico de la Calificación Crediticia de las Finanzas Públicas Estatales en México: Redes Neuronales Artificiales, Modelo PROBIT Ordenado y Análisis Discriminante. Comité de Investigación del Premio Nacional de Mercados Financieros de la Bolsa Mexicana de Valores. Artículo de Divulgación Año II. Volumen II, Julio-Diciembre 2010, 1-37.

Hamid, S. y Habib, A. (2005). Can Neural Networks Learn the Black-Scholes Model? A simplified approach. Working paper No. 2005-01. The Center for Financial Studies, Southern New Hampshire University.

Haykin, S. (1999). Neural Networks. A Comprehensive Foundation. USA: MacMillan College Publishing Company.

Hornik, K. (1991). Approximation Capabilities of Multilayer Feedforward Networks. Neural Networks, 4, pp. 251-257.

Hornik, K., Stinchcombe, M. and White, H. (1989). Multilayer Feeforward Networks are Universal Approximators, Neural Networks, 2, pp. 359-366.

Hutchinson, J., Lo, A y Poggio, T. (1994). A non-parametric approach to pricing and hedging derivative securities via learning networks, Journal of Finance, 49, pp. 881-889.

Johnson, C. y Padilla, M. (2005). Regularidades no lineales en índices accionarios: una aproximación con redes neuronales. El Trimestre Económico, 72(4), issue 288, pp. 765821

Lamothe, P. y García, P. (2004). La volatilidad implícita en las opciones sobre índices bursátiles: Propuesta de Metodología de Estimación. (Documento de Trabajo 0407. Doctorado en Finanzas de Empresa, Universidad Autónoma y Universidad Complutense de Madrid), pp. 1-16. Recuperado de dialnet.unirioja.es/servlet/fichero _articulo?codigo $=2480062 . p d f$

Moller, M.F. (1993). Scaled Conjugate Gradient Algorithm for Fast Supervised Learning. Neural Networks, 6 (4), pp. 525-533.

Moyer, C., Mcguigan, J. y Kretlow, W. (2004). Administración Financiera Contemporánea. Novena Edición. México, D.F.: Editorial Thompson, pp. 178-190.

Oddone, C. N. (2004). Mercados Emergentes y Crisis Financiera Internacional: El Caso Argentino a la Luz de las Experiencias de México y el Sudeste Asiático. Eumednet. Buenos Aires, Argentina.

Parisi, A. (2002). Evaluación de Modelos de Redes Neuronales de Predicción del Signo de la Variación del IPSA. Estudios de Administración, Chile, 9(1), pp. 67-103.

Parisi, A., Parisi, F. y Guerrero, J. L. (2003). Redes neuronales en la predicción de Índices bursátiles internacionales: Un análisis de la estabilidad de los pesos. El Trimestre Económico, 69(280), Octubre-Diciembre, pp. 721-744. 
Qi, M. (1999). Nonlinear Predictability of Stock Returns Using Financial and Economic Variables. Journal of Business and Economic Statistics, 17(4), pp. 419-429.

Sánchez, J. (2003). Dos Aplicaciones Empíricas de las Redes Neuronales Artificiales a la Clasificación y la Predicción Financiera en el Mercado Español. Revista Asturiana de Economía, 28, pp. 61-87.

Shah, J. y Murtaza M. (2000). A Neural Network Based Clustering Procedure for Bankruptcy Prediction. American Business Review, 18(2), pp. 80-86.

Standard and Poors. (2009). Guía Sobre Aspectos Fundamentales de las Calificaciones Crediticias. México, 12.

Van Eyden, R. J. (1996). The Applications of Neural Networks in the Forecasting of Share Prices. New York: Finance \& Technology Publishing.

Zhang, D., Jiang, Q. y Li, X. (2004). Application of Neural Networks in Financial Data Mining. International Journal of Computational Intelligence, 1(2), pp. 116-119. 